\title{
GPR109A (PUMA-G/HM74A) mediates nicotinic acid-induced flushing
}

\author{
Zoltán Benyó,, ${ }^{1}$ Andreas Gille, ${ }^{1}$ Jukka Kero, ${ }^{1}$ Marion Csiky, ${ }^{1}$ Marie Catherine Suchánková, ${ }^{1}$ \\ Rolf M. Nüsing, ${ }^{2}$ Alexandra Moers, ${ }^{1}$ Klaus Pfeffer, ${ }^{3}$ and Stefan Offermanns ${ }^{1}$
}

1Institute of Pharmacology, University of Heidelberg, Heidelberg, Germany. 2Institute of Clinical Pharmacology, Johann Wolfgang Goethe-University Frankfurt, Frankfurt, Germany. ${ }^{3}$ Institute of Medical Microbiology, University of Düsseldorf, Düsseldorf, Germany.

\begin{abstract}
Nicotinic acid (niacin) has long been used as an antidyslipidemic drug. Its special profile of actions, especially the rise in HDL-cholesterol levels induced by nicotinic acid, is unique among the currently available pharmacological tools to treat lipid disorders. Recently, a G-protein-coupled receptor, termed GPR109A (HM74A in humans, PUMA-G in mice), was described and shown to mediate the nicotinic acid-induced antilipolytic effects in adipocytes. One of the major problems of the pharmacotherapeutical use of nicotinic acid is a strong flushing response. This side effect, although harmless, strongly affects patient compliance. In the present study, we show that mice lacking PUMA-G did not show nicotinic acid-induced flushing. In addition, flushing in response to nicotinic acid was also abrogated in the absence of cyclooxygenase type 1 , and mice lacking prostaglandin $\mathrm{D}_{2}\left(\mathrm{PGD}_{2}\right)$ and prostaglandin $\mathrm{E}_{2}\left(\mathrm{PGE}_{2}\right)$ receptors had reduced flushing responses. The mouse orthologue of GPR109A, PUMA-G, is highly expressed in macrophages and other immune cells, and transplantation of wild-type bone marrow into irradiated PUMA-G-deficient mice restored the nicotinic acid-induced flushing response. Our data clearly indicate that GPR109A mediates nicotinic acid-induced flushing and that this effect involves release of $\mathrm{PGE}_{2}$ and $\mathrm{PGD}_{2}$, most likely from immune cells of the skin.
\end{abstract}

\section{Introduction}

Nicotinic acid (niacin) has been known for decades to decrease the plasma concentration of cholesterol, free fatty acids, and triglycerides in humans $(1,2)$, and these effects have been used to treat dyslipidemic states $(3,4)$. Interestingly, nicotinic acid compared with other lipid-lowering drugs strongly raises HDL cholesterol $(5,6)$ while plasma concentrations of VLDL and LDL cholesterol as well as lipoprotein(a) are lowered by nicotinic acid $(3,4)$. Evidence has recently been provided that nicotinic acid is beneficial as an additive therapy to statins in the treatment of patients with relatively low HDL cholesterol levels (7-11).

The major unwanted effect of nicotinic acid when given at pharmacologically active doses is flushing. Although harmless, this side effect limits patient compliance. Nicotinic acid-induced flushing can be observed even at relatively low doses (50-100 mg per os) and consists of a cutaneous vasodilation accompanied by a burning sensation mainly affecting the upper body and face $(12,13)$. Flushing develops rapidly in virtually every patient taking nicotinic acid and lasts for about 1 hour. When nicotinic acid is given repeatedly, tolerance to nicotinic acid-induced flushing develops within days while the lipid-lowering effects are stable over time (14). The fact that nicotinic acid-induced flushing could be reduced by cyclooxygenase inhibitors like indomethacin, which do not affect the wanted effects of nicotinic acid (15-17) suggests that prostanoids are involved in nicotinic acid-induced flushing. Further evidence for an involvement of prostanoids in nicotinic acid-induced flushing was provided by the finding that levels of

Nonstandard abbreviations used: $\left[\mathrm{Ca}^{2+}\right]$, intracellular $\left[\mathrm{Ca}^{2+}\right]$; DP, $\mathrm{PGD}_{2}$ receptor; $\mathrm{EP}_{2}$, type $2 \mathrm{PGE}_{2}$ receptor; $\mathrm{IP}, \mathrm{PGI}_{2}$ receptor; $\mathrm{LD}$, laser Doppler; $\mathrm{LDF}$, LD flux; $\mathrm{PLA}_{2}$, phospholipase $\mathrm{A}_{2} ; \mathrm{PGD}_{2}$, prostaglandin $\mathrm{D}_{2} ; \mathrm{PGE}_{2}$, prostaglandin $\mathrm{E}_{2} ; \mathrm{PGI}_{2}$, prostaglandin $\mathrm{I}_{2}$; PUMA-G, protein upregulated in macrophages by interferon- $\gamma$.

Conflict of interest: The authors have declared that no conflict of interest exists.

Citation for this article: J. Clin. Invest. 115:3634-3640 (2005).

doi:10.1172/JCI23626. the vasodilatory prostanoids prostaglandin $\mathrm{I}_{2}\left(\mathrm{PGI}_{2}\right)$, prostaglandin $\mathrm{E}_{2}\left(\mathrm{PGE}_{2}\right)$, and prostaglandin $\mathrm{D}_{2}\left(\mathrm{PGD}_{2}\right)$ and their metabolites increased after oral administration of nicotinic acid (15-20). The most dramatic increase was described for the $\mathrm{PGD}_{2}$ metabolite $9 \alpha, 11 \beta-\mathrm{PGF}_{2}(20)$. $\mathrm{PGI}_{2}$ and $\mathrm{PGD}_{2}$ formation decreased after repetitive administration of nicotinic acid in parallel with the development of tolerance to nicotinic acid-induced flushing (18, 21). While these data suggest that prostanoids, especially $\mathrm{PGD}_{2}$, mediate nicotinic acid-induced flushing, the mechanism of nicotinic acid-induced prostanoid formation remains obscure.

Recently, a G-protein-coupled receptor for nicotinic acid termed GPR109A (HM74A in humans and PUMA-G in mice) has been identified (22-24). The receptor is expressed in adipocytes and immune cells and couples to $\mathrm{G}_{\mathrm{i}}$-type $\mathrm{G}$-proteins. In adipose cells, activation of the receptor by nicotinic acid is supposed to lower cAMP levels, resulting in a decreased activity of hormone-sensitive lipase and reduced hydrolysis of triglycerides to free fatty acids. Consistent with this, the nicotinic acid-induced antilipolytic effect resulting in decreased free fatty acid and triglyceride plasma levels was abrogated in mice lacking PUMA-G (23).

The aim of the present study was to analyze the mechanism of nicotinic acid-induced flushing and to test whether the recently discovered nicotinic acid receptor is involved in this effect. Using various genetic mouse models, we show that nicotinic acid-induced cutaneous vasodilation in mice requires PUMA-G and COX-1. In addition, we demonstrate that the effect involves both $\mathrm{PGD}_{2}$ and $\mathrm{PGE}_{2}$ receptors (DP and $\mathrm{EP}_{2}$, respectively). These data provide new insight into the mechanism of nicotinic acid-induced flushing and will be of importance for the development of new lipid-lowering drugs based on the recently discovered nicotinic acid receptor.

\section{Results}

To study the mechanism of nicotinic acid-induced flushing in genetic mouse models, we established a procedure to determine 

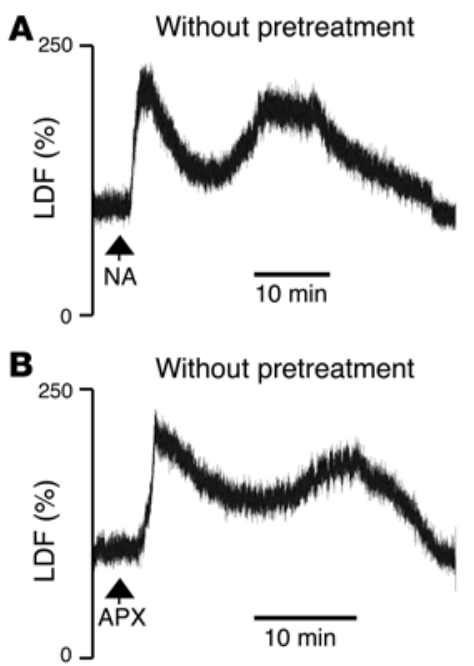
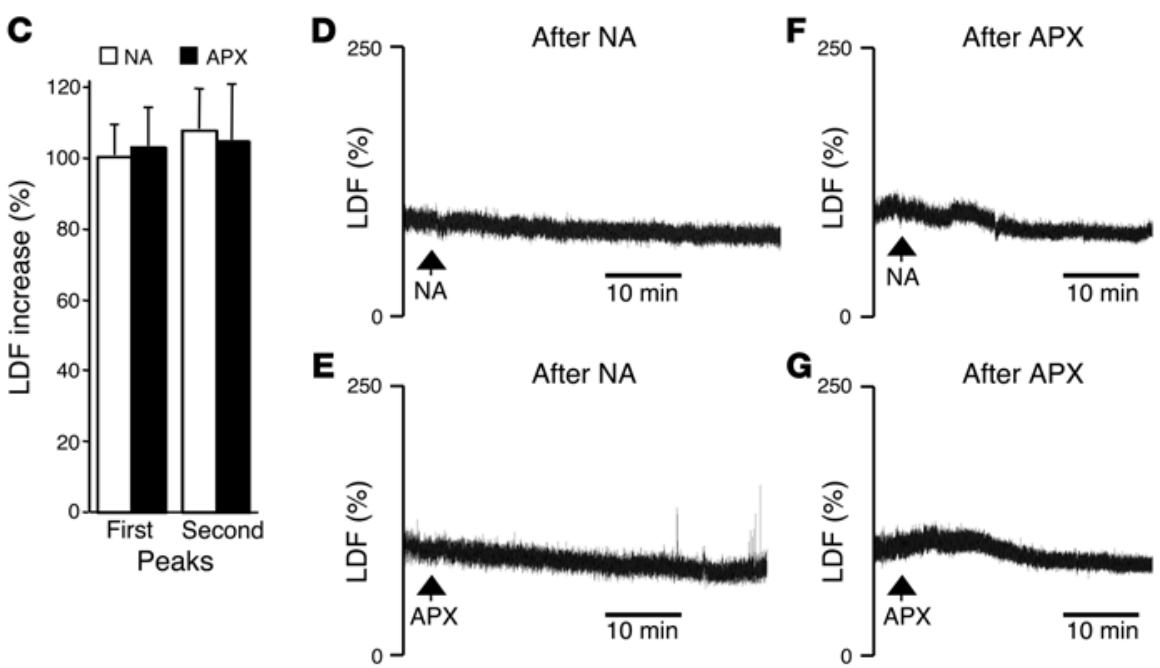

Figure 1

Nicotinic acid-and acipimox-induced flushing response in the mouse external ear and its desensitization. (A and B) Original recordings of the LDF signal in the ear artery. Mean baseline LDF represents $100 \%$ on the vertical scale. Nicotinic acid (NA) or acipimox (APX) were injected i.p. in doses of $200 \mathrm{mg} / \mathrm{kg}$ at the time points indicated by arrows. (C) Quantitative analysis of the percentage of LDF increase after administration of NA (white bars, $n=21$ ) and APX (black bars, $n=11$ ) during the first and second peaks of flushing. (D-G) Animals were pretreated with 200 $\mathrm{mg} / \mathrm{kg}$ (i.p.) of NA ( $\mathbf{D}$ and $\mathbf{E}$ ) or APX ( $\mathbf{F}$ and $\mathbf{G}) 120$ minutes before the administration of NA ( $\mathbf{D}$ and $\mathbf{F}$ ) or APX (E and $\mathbf{G})$. Shown are representative recordings of $5-6$ experiments per group.

cutaneous vasodilation in the mouse ear using laser-Doppler (LD) flowmetry. Injection of nicotinic acid i.p. resulted in a dose-dependent and transient increase in blood flow, which started within 2 minutes after administration (Figure 1, A and C). Maximal effects were observed at nicotinic acid doses of $100-200 \mathrm{mg} / \mathrm{kg}$. In all experiments, a biphasic increase in flow could be observed with a first peak after about 3-4 minutes and a second peak after about 25 minutes. At 40-50 minutes after nicotinic acid injection, blood flow returned to basal levels. This effect was not accompanied by any measurable change in blood pressure or heart rate (data not shown). Acipimox, which is structurally related to nicotinic acid and shares its pharmacological properties (25-27), also induced a biphasic cutaneous vasodilation in mice (Figure 1, B and C). Flushing induced by nicotinic acid and acipimox has been shown to be subject to rapid tolerance development in humans. Consistent with this, readministration of nicotinic acid or acipimox within 120 minutes resulted in minor or no vasodilatory effect, and there was cross-tolerance between the effects of nicotinic acid and acipimox (Figure 1, D-G).

To analyze the mechanism of nicotinic acid-induced flushing, we tested the effect of nicotinic acid on cutaneous vasodilation in mice that lack COX-1 (28) or eNOS (29) (Figure 2). Mice deficient in eNOS showed flushing in response to nicotinic acid that was indistinguishable from flushing induced in wild-type animals (Figure 2, A-C). In contrast, mice lacking COX-1 did not respond with any increase in cutaneous blood flow to nicotinic acid (Figure 2, D-F). These data clearly show that nicotinic acid-induced flushing is completely dependent on COX-1 and subsequent formation of prostanoids while endothelial NO production does not play a critical role.

In humans, nicotinic acid has been shown to strongly increase plasma levels of the $\mathrm{PGD}_{2}$ metabolite $9 \alpha, 11 \beta-\mathrm{PGF}_{2}(20,21)$ and to a lesser extent, $\mathrm{PGE}_{2}$ and $\mathrm{PGI}_{2}(15-19)$. Injection of $\mathrm{PGD}_{2}$ and $\mathrm{PGI}_{2}$ i.p. resulted in a monophasic increase in cutaneous blood flow while systemic application of $\mathrm{PGE}_{2}$ caused a transient increase followed by a drop in blood pressure (data not shown).

Vasodilatory effects of $\mathrm{PGD}_{2}, \mathrm{PGI}_{2}$, and $\mathrm{PGE}_{2}$ are mediated by DPs, $\mathrm{PGI}_{2}$ receptors (IPs), and the type 2 or type $4 \mathrm{PGE}_{2}$ receptors $\left(\mathrm{EP}_{2} \mathrm{~S}\right.$ or $\mathrm{EP}_{4} \mathrm{~S}$, respectively) (30-32). To test whether 1 or several of these vasodilatory prostanoids mediate nicotinic acid-induced cutaneous vasodilation, we measured cutaneous blood flow of DP-, $\mathrm{EP}_{2-}, \mathrm{EP}_{4}$, and IP-deficient mice (33-36) in response to nicotinic acid. As shown in Figure 3, D and E, nicotinic acid-induced flushing was normal in mice lacking the IP. However, there was a significant decrease in the first peak of nicotinic acid-induced increase in blood flow in DP-, $\mathrm{EP}_{2^{-}}$, and $\mathrm{EP}_{4}$-deficient animals while the second peak was decreased in $\mathrm{EP}_{2}$ - and $\mathrm{EP}_{4}$ - but not in DP-deficient mice (Figure 3, $\mathrm{A}-\mathrm{C}$ and $\mathrm{E}$ ). These data clearly indicate that the nicotinic acid-induced flushing response involves $\mathrm{PGD}_{2}$ and $\mathrm{PGE}_{2}$ but not $\mathrm{PGI}_{2}$.

The recent identification of GPR109A as a receptor for nicotinic acid raises the question of whether this receptor, which has been shown to mediate the antilipolytic effects of nicotinic acid, is also involved in nicotinic acid-induced flushing. Mice deficient for the murine form of GPR109A, PUMA-G, did not respond with any measurable change in cutaneous blood flow to nicotinic acid while mice heterozygous for a null allele of PUMA-G showed a flushing response comparable to wild-type animals (Figure 4, A-C and E). Administration of $\mathrm{PGD}_{2}$ (Figure 4D) or serotonin (data not shown) to PUMA-G ${ }^{-/-}$mice induced a full flushing response, indicating that PUMA-G-deficient mice had not lost the ability to flush in general. Thus, PUMA-G mediates both nicotinic acid-induced antilipolysis (23) and cutaneous vasodilation.

PUMA-G as well as its human orthologue HM74A are expressed in adipose cells as well as in various immune cells, including macrophages $(22-24,37)$. Northern blot analysis clearly showed that PUMA-G is also expressed in the external ear (Figure 5A). RTPCR analysis of skin prepared from various regions, including the ear, indicated PUMA-G expression in the skin (Figure 5B). To 


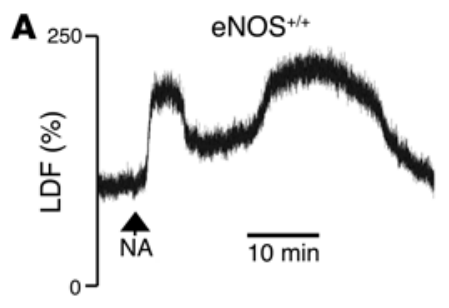

B

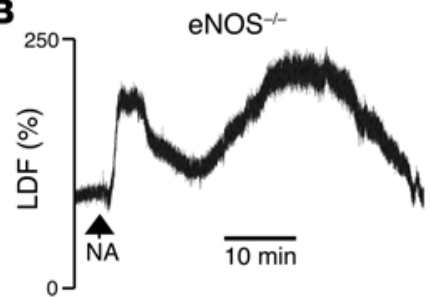

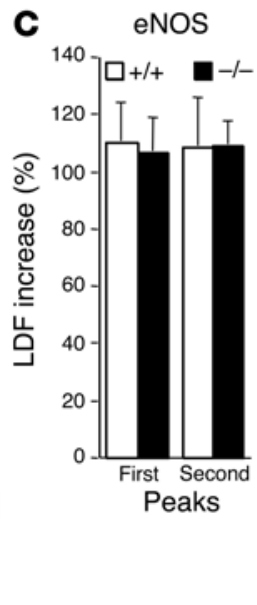


Figure 2

COX-1 but not eNOS is required for NA-induced flushing. (A-C) Original LDF recordings (A and $\mathbf{B}$ ) and quantitative analysis of the percentage of LDF increase (C) after i.p. administration of $200 \mathrm{mg} / \mathrm{kg} \mathrm{NA}$ indicate normal first and second peaks of the flushing response in eNOS $-1-$ mice (B and $\mathbf{C}$, black bars, $n=9$ ) compared with wild-type littermate controls ( $\mathbf{A}$ and $\mathbf{C}$, white bars, $n=9$ ). (D-F) Original LDF recordings (D and $\mathbf{E})$ and quantitative analysis of the percentage of LDF increase $(\mathbf{F})$ after administration of NA to COX-1-/- mice $(\mathbf{E}$ and $\mathbf{F}$, black bars, $n=7)$ and wild-type littermates (D and $\mathbf{F}$, white bars, $n=6) .{ }^{* \star} P=0.002,{ }^{* \star *} P<0.001$ vs. COX-1 ${ }^{+/+}$.

obtain further information about the cell type which may mediate nicotinic acid-induced flushing, we isolated various immune cells from skin and other organs. RT-PCR revealed expression of PUMA-G in MHC class II-positive skin cells and dendritic cells as well as in peritoneal macrophages whereas no expression could be seen in peripheral monocytes (Figure 5C). To test whether macrophages are able to respond to nicotinic acid via PUMA-G, we determined intracellular-free $\left[\mathrm{Ca}^{2+}\right]$ in Fura-2-loaded macrophages. While wild-type cells responded with a transient increase in $\left[\mathrm{Ca}^{2+}\right]_{i}$, PUMA-G-deficient macrophages were completely unre-

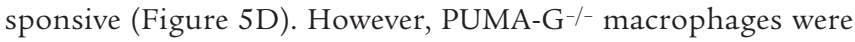
still able to respond to ATP (Figure 5D).

To test whether immune cells mediate nicotinic acid-induced flushing, we generated bone marrow chimeras by transplanting wild-type bone marrow or bone marrow from PUMA-G $\mathrm{G}^{-/}$mice into irradiated PUMA-G-deficient animals. The potential of nicotinic acid to induce flushing was tested before transplantation and in 4 week intervals after transplantation. Before and up to 8 weeks after bone marrow transplantation, PUMA-G-deficient mice transplanted with wild-type or PUMA-G-deficient bone marrow did not flush in response to nicotinic acid. However, 12 weeks after transplantation, PUMA-G ${ }^{-1}$ mice that had received wild-type bone marrow started to show cutaneous vasodilation in response to nicotinic acid. The responsiveness of transplanted PUMA-G ${ }^{-/-}$mice to nicotinic acid was accompanied by the expression of PUMA-G in the bone marrow as well as in bone marrow-derived dermal cells (Figure 6A). PUMA-G-deficient animals transplanted with PUMA-Gdeficient bone marrow remained unresponsive (Figure 6, B and C). The fact that wild-type bone marrow was able to restore the nicotinic acid-induced flushing response in PUMA-G-deficient animals clearly shows that bone marrow-derived cells expressing PUMA-G mediate the nicotinic acid-induced flushing reaction.
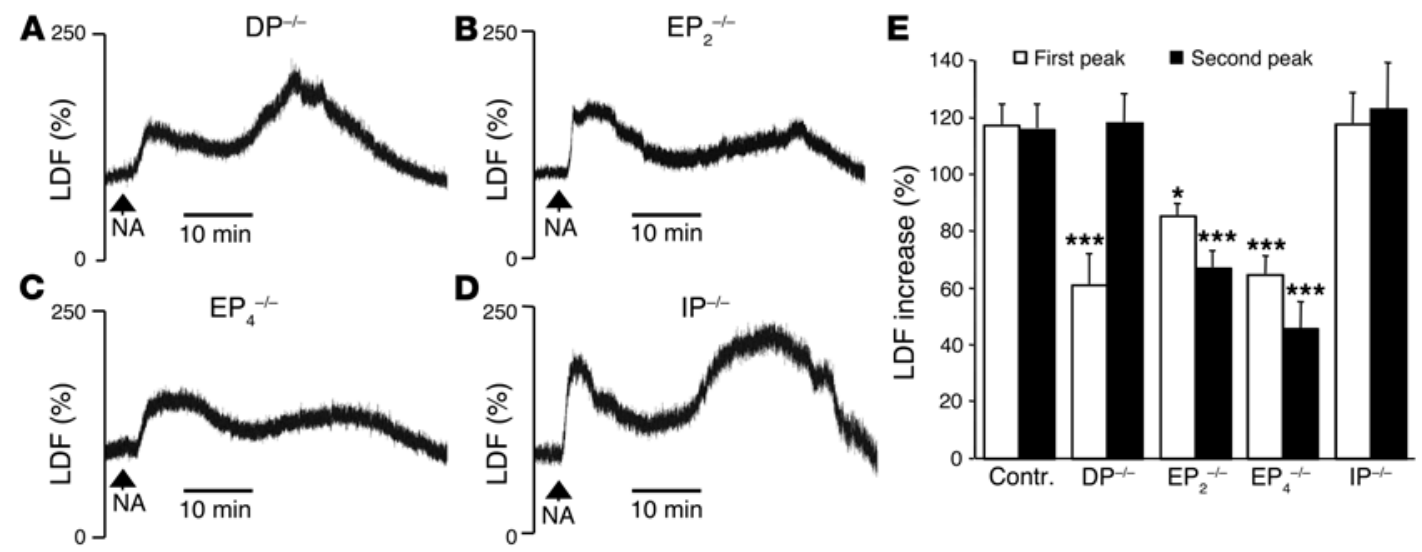

Figure 3

NA-induced flushing involves $\mathrm{EP}_{2}, \mathrm{EP}_{4}$, and DP but not IP. (A-D) Original recordings of the flushing response to nicotinic acid (200 mg/kg i.p.) in $\mathrm{DP}^{-1-}(\mathbf{A}), \mathrm{EP}_{2}^{-/-}(\mathbf{B}), \mathrm{EP}_{4}^{-/-}(\mathbf{C})$, and IP $\mathrm{P}^{-/-}$mice (D). (E) Quantitative analysis of the percentage of LDF increase in response to NA in wild-type control animals $(n=27)$ and the indicated mutants $(n=6-15)$. ${ }^{*} P=0.013$; ${ }^{* *} P<0.001$ vs. control (contr.). 


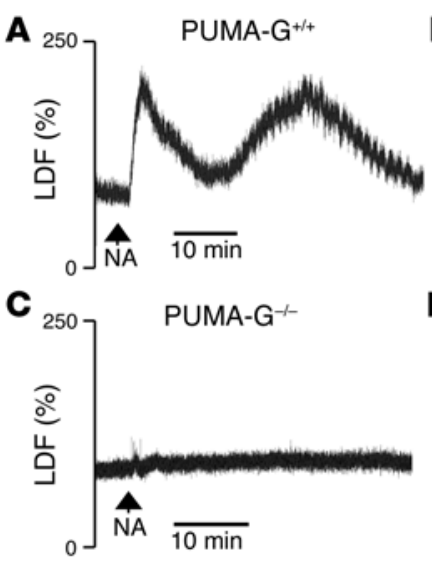

E



\section{Figure 4}

PUMA-G mediates the flushing response to NA. (A-D) Original recordings of the LDF response to i.p. injection of $200 \mathrm{mg} / \mathrm{kg} \mathrm{NA}(\mathbf{A}-\mathbf{C})$ or 2 $\mathrm{mg} / \mathrm{kg} \mathrm{PGD}_{2}$ (D) in PUMA-G ${ }^{+/+}(\mathbf{A})$, PUMA-G ${ }^{+/-}$(B), and PUMA-G ${ }^{-/-}$(C and $\mathrm{D}$ ) mice. (E) Quantitative analysis of the percentage of LDF increase after administration of NA in PUMA-G ${ }^{+/+}$ (white bars, $n=8$ ), PUMA-G+/- (gray bars, $n=10$ ), and PUMA-G ${ }^{-/-}$(black bars, $n=10$ ) mice. ${ }^{* \star *} P<0.001$ vs. PUMA-G ${ }^{+/+}$littermate controls.

\section{Discussion}

Nicotinic acid is one of the oldest drugs to treat dyslipidemia. It decreases VLDL synthesis and lowers LDL cholesterol levels while being the best available agent for increasing HDL cholesterol (38, 39). Despite its versatile beneficial effects, the clinical use of nicotinic acid has been limited by its side effects. Most prominently, the flushing response consisting of cutaneous vasodilation accompanied by a burning sensation occurs in virtually all patients receiving nicotinic acid and negatively affects compliance $(4,14)$. Characteristic differences between the effect of nicotinic acid on lipids and nicotinic acid-induced flushing have been observed with regard to the underlying mechanism. While the flushing response abates after repeated administration of nicotinic acid within days, the antidyslipidemic effect is stable even after long-term treatment (4, 14). In addition, initial flushing can be reduced by coadministra- tion of nonsteroidal antiinflammatory agents, which do not affect nicotinic acid effects on lipid levels (40). The recent identification of GPR109A as a G protein-coupled receptor for which nicotinic acid is a high-affinity ligand (22-24) opens new approaches to study the mechanisms of the pharmacological effects of nicotinic acid. While the receptor has been shown to mediate the antilipolytic effects of nicotinic acid on adipocytes and the subsequent decrease in free fatty acid and triglyceride levels, it is not clear whether the receptor is also involved in nicotinic acid-induced HDL cholesterol elevation and flushing. In the present paper, we provide evidence that the murine form of GPR109A, PUMA-G, mediates nicotinic acid-induced cutaneous vasodilation.

The phenomenon of a rapid cutaneous vasodilation in response to nicotinic acid and related drugs is not restricted to humans but can also be seen in other mammalian species $(15,41)$. We showed

\section{Figure 5}

PUMA-G is expressed in the skin and in various immune cells. (A) Northern blot analysis of PUMA-G mRNA in the ear and brown adipose tissue (BAT) of PUMA-G $^{+/+}$(WT) and PUMA-G-/- (KO) animals. $18 \mathrm{~s}$, ribosomal RNA used as control. (B) RT-PCR of cDNAs from different tissues prepared from PUMA- $\mathrm{G}^{+/+}$ (WT) and PUMA-G ${ }^{-/-}(\mathrm{KO})$ mice using PUMA-G- or GAPDH-specific primers. (C) Expression of PUMA-G in dermal MHC class II-positive cells, dendritic cells, and peritoneal macrophages. (D) Effect of NA $(100 \mu \mathrm{M})$ and ATP $(10 \mu \mathrm{M})$ on the $\left[\mathrm{Ca}^{2+}\right]_{i}$ in macrophages prepared from wild-type or PUMA-G-deficient mice. Values on the $y$ axis indicate the measured 340/380-nm fluorescence ratio as an indicator of the intracellularfree $\left[\mathrm{Ca}^{2+}\right]$.

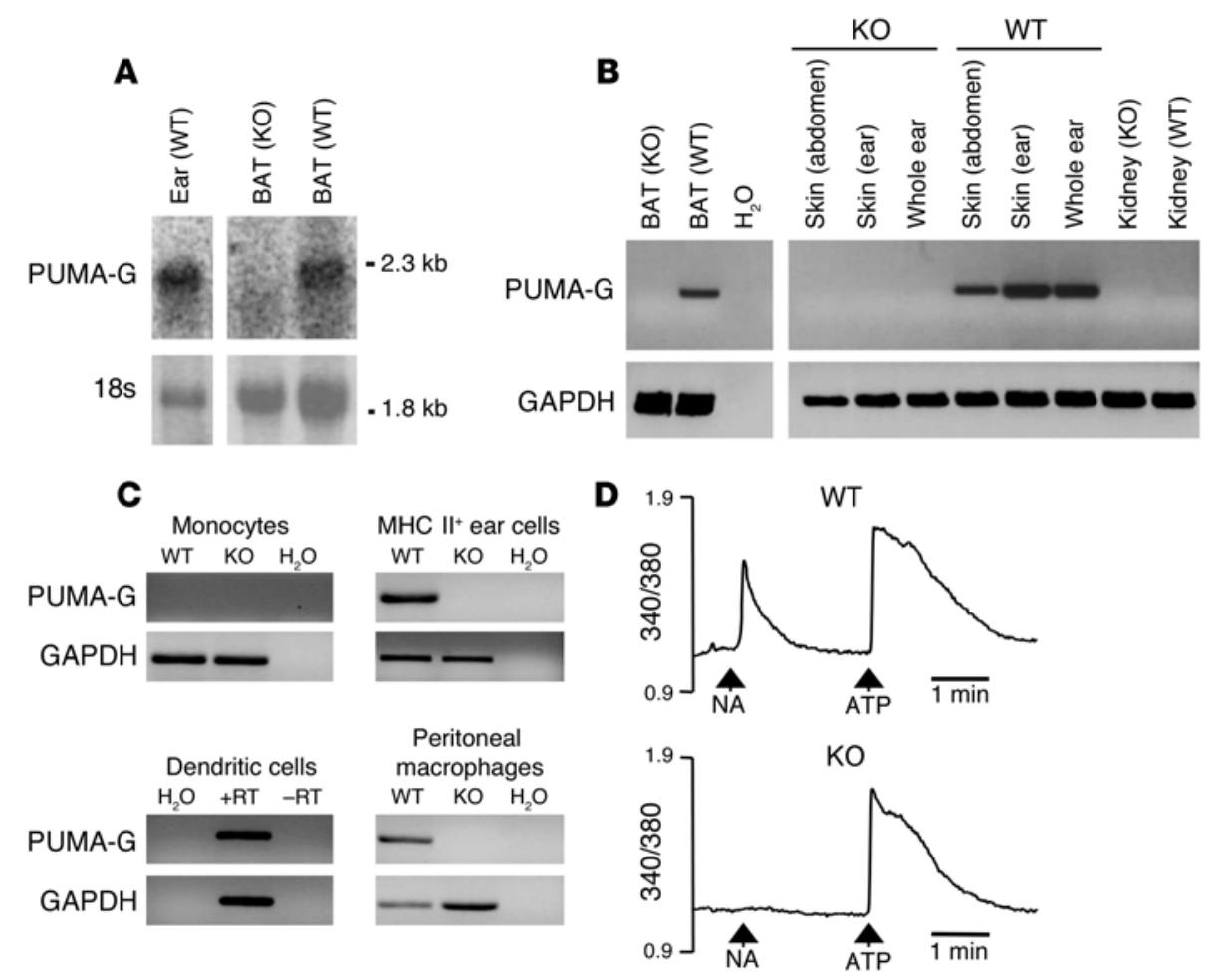



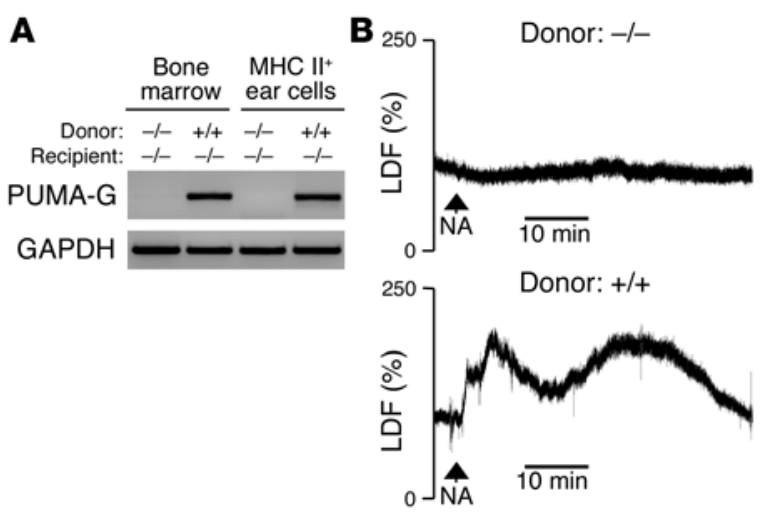

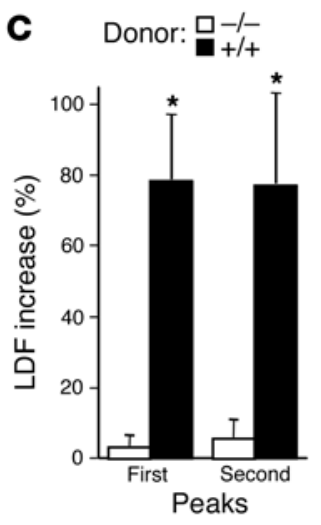

Figure 6

Transplantation of wild-type bone marrow to PUMA-G-deficient recipients restores the flushing response to NA. (A) RT-PCR of cDNAs from BM or MHC class II-positive cells from the outer ear of PUMA-G-deficient mice transplanted with wild-type BM or PUMA-Gdeficient bone marrow using PUMA-G- or GAPDH-specific primers. (B) Original LDF recordings of the flushing response induced by $200 \mathrm{mg} / \mathrm{kg}$ NA injected i.p. at the time points indicated by arrows. The experiments were performed 20 weeks after transplantation of PUMA-G ${ }^{+/+}$(lower panel) or PUMA-G ${ }^{-/-}$(upper panel) BM to PUMA-G ${ }^{-/-}$recipients. (C) Statistical evaluation of NA effects on LDF in PUMA-G ${ }^{-/}$mice transplanted with wildtype $(n=8)$ or $\mathrm{PUMA}^{-\mathrm{G}^{-/}}$bone marrow $(n=5) .{ }^{*} P<0.05$ vs. animals transplanted with PUMA-G ${ }^{-1-}$ bone marrow.

that nicotinic acid and its analogue acipimox induce an increase in cutaneous blood flow in mice also. The effect showed strong tachyphylaxis similar to the situation in humans (13). We consistently observed a biphasic response to both nicotinic acid and acipimox. A similar phenomenon has been described in humans receiving nicotinic acid orally (13).

Vasodilatory effects are in most cases mediated by an increase in cGMP or cAMP concentrations in vascular smooth muscle cells via activation of guanylyl cyclases by nitric oxide or via adenylyl cyclases by agents activating $\mathrm{G}_{\mathrm{s}}$-coupled receptors, respectively (42). Our data indicate that the nitric oxide/guanylyl cyclase pathway is unlikely to be involved in nicotinic acid-induced vasodilation since mice lacking eNOS showed a normal flushing response to nicotinic acid. Based on observations in humans (see above), cyclooxygenase-mediated prostanoid production has been suggested as playing a role in the flushing response to nicotinic acid. Consistent with this, mice lacking COX-1 did not show any flushing after administration of nicotinic acid, indicating that COX-1 indeed plays a central role in mediating this effect. At least 3 prostanoids with the potential to induce vasodilatory effects are produced in a COX-1-dependent manner: $\mathrm{PGI}_{2}, \mathrm{PGD}_{2}$, and $\mathrm{PGE}_{2}$, which act through the $\mathrm{G}_{5}$-coupled IP, DP, and $\mathrm{EP}_{2} / \mathrm{EP}_{4}$, respectively $(31,32,43)$. For all 3 prostanoids and their metabolites, an increase in plasma or urine levels has been described in humans treated with nicotinic acid. While increases in $\mathrm{PGI}_{2}$ and $\mathrm{PGE}_{2}$ are rather moderate, a 400 - to 800 -fold increase in plasma levels of the $\mathrm{PGD}_{2}$ metabolite $9 \alpha, 11 \beta-\mathrm{PGF}_{2}$ has been observed after administration of nicotinic acid (20). However, the relevance of individual prostanoids for nicotinic acid-induced flushing is unclear. To test whether any of the 3 prostanoids is involved in nicotinic acidinduced flushing, we used mice lacking DP, $\mathrm{EP}_{2}, \mathrm{EP}_{4}$, or IP. (44) Interestingly, IP-deficient mice showed normal flushing responses to nicotinic acid while the responses were significantly reduced in mice lacking DP, $\mathrm{EP}_{2}$, or $\mathrm{EP}_{4}$. However, none of the prostanoid receptor-deficient mice showed complete abrogation of nicotinic acid-induced flushing in contrast to COX-1-deficient animals. We conclude from these studies that both $\mathrm{PGD}_{2}$ and $\mathrm{PGE}_{2}$ but not $\mathrm{PGI}_{2}$ mediate the nicotinic acidinduced flushing response.

The phospholipase $\mathrm{A}_{2}$-mediated ( $\mathrm{PLA}_{2}$-mediated) formation of arachidonic acid, which is rapidly metabolized to prostanoids and other eicosanoids depending on the available enzyme systems, is the rate-limiting step in the acute biosynthesis and release of prostanoids. $\mathrm{PLA}_{2}$ activation initiated through the activation of G-protein-coupled receptors involves the activation of protein kinases or the elevation of the cytosolic $\left[\mathrm{Ca}^{2+}\right.$, which can then activate $\mathrm{PLA}_{2}$ $(45,46)$. The $\mathrm{G}_{\mathrm{i}}$-coupled nicotinic acid receptor is mainly expressed in adipocytes and immune cells, including macrophages $(22-24,37)$. Although adipocytes can form a variety of prostanoids $(47,48)$, nicotinic acid-induced prostanoid formation responsible for flushing has been suggested as taking place in the skin (49). The fact that nicotinic acid-induced flushing can be restored in irradiated PUMA-G-deficient mice transplanted with wild-type bone marrow strongly indicates that immune cells mediate the effect. It is well known that in leukocytes, activation of $\mathrm{G}_{i}$ via $\beta \gamma$ subunit-mediated phospholipase $\mathrm{C}$ activation results in an increase in the intracellular $\left[\mathrm{Ca}^{2+}\right]\left(\left[\mathrm{Ca}^{2+}\right]_{i}\right)(50,51)$ and consecutive $\mathrm{PLA}_{2}$ activation. Consistent with this, we found that in macrophages, nicotinic acid induces an increase in $\left[\mathrm{Ca}^{2+}\right]_{\mathrm{i}}$ via its receptor PUMA-G. Future work will have to identify the exact cell type responsible for nicotinic acid-induced prostanoid formation via the nicotinic acid receptor. Mast cells are unlikely to be involved, as nicotinic acid treatment does not result in a measurable systemic histamine accumulation (20). In addition, we have observed a normal flushing response in the mast cell-deficient mouse mutant WBB6F1-Kit $/{ }^{\mathbb{W}} / \mathrm{Kit}^{\mathrm{W}-\mathrm{v}}(52,53)$ (data not shown). Other dermal immune cells, such as those of the monocyte/macrophage lineage, which are able to synthesize various prostanoids (54-56), are good candidates that may execute the nicotinic acidinduced prostaglandin-mediated flushing reaction.

Taken together, we have identified the nicotinic acid receptor GPR109A as a critical mediator of nicotinic acid-induced flushing. This indicates that it will be difficult to pharmacologically dissociate the antilipolytic and vasodilatory effects of nicotinic acid by using potentially new agonists acting on GPR109A. However, our data clearly indicate that nicotinic acid-induced flushing is an indirect effect mediated by GPR109A-dependent production of $\mathrm{PGD}_{2}$ and $\mathrm{PGE}_{2}$ by bone marrow-derived immune cells and that the $\mathrm{PGE}_{2}$ and $\mathrm{PGD}_{2}$ synthesizing enzymes and the $\mathrm{DP}$ and $\mathrm{EP}_{2} / \mathrm{EP}_{4}$ represent potential targets to suppress nicotinic acid-induced flushing.

\section{Methods}

Mice. Experiments were carried out in wild-type and genetically altered adult mice (body weight $20-30 \mathrm{~g}$ ) on a C57BL/6 background. Wild-type and eNOS ${ }^{-/}$animals were obtained from Charles River Laboratories, COX-1/mice were from Ingvar Bjarnason (Department of Medicine, Guy's, King's College, St. Thomas' School of Medicine, London, United Kingdom), and prostanoid receptor-deficient mice were from Shuh Narumiya (Kyoto 
University, Kyoto, Japan). When testing KO animals, wild-type littermates served as controls. Mice were housed in temperature-controlled facilities on a 12-hour light-dark cycle with ad libitum food and water access. All experimental procedures were approved by the Animal Care and Use Committee at the Regierungspräsidium Karlsruhe, Karlsruhe, Germany.

Measurement of flush. Mice were anesthetized by i.p. injection of 60 $\mathrm{mg} / \mathrm{kg}$ pentobarbital (Narcoren; Merial) and placed on their left sides on a controlled heating pad (TKM-0902; Föhr Medical Instruments) in order to maintain a rectal temperature between 35.5 and $37.5^{\circ} \mathrm{C}$. Using adhesive strip and a $\mathrm{PH}$ 07-5 miniholder, a small straight $\mathrm{LD}$ probe (No. 407; Perimed) was attached to the dorsal surface of the right ear over a first order branch of the ear artery. LD flux (LDF) was continuously recorded by a PeriFlux $5001 \mathrm{LD}$ monitor (Perimed) connected to a PC via the MP100 system (Biopac Systems Inc.). Recordings were analyzed offline with AcoKnowledge 3.7.3 software (Biopac Systems Inc.). After a 10-minute stabilization period, tested compounds were injected i.p. Nicotinic acid and acipimox were prepared in 5\% (2-hydroxypropyl)- $\beta$-cylodextrin, and the $\mathrm{pH}$ of solutions was adjusted to 6.9-7.1 with $1 \mathrm{M} \mathrm{NaOH}$. These agents were applied in a dose of $200 \mu \mathrm{g} / \mathrm{g}$ body weight in a volume of $20 \mu \mathrm{l} / \mathrm{g}$. $\mathrm{PGD}_{2}, \mathrm{PGE}_{2}$, and $\mathrm{PGI}_{2}$ (Cayman Chemical Co.) were dissolved in DMSO and diluted 20 times with saline. The dose of prostanoids was $2 \mu \mathrm{g} / \mathrm{g}$ in a volume of $4 \mu \mathrm{l} / \mathrm{g}$. None of the vehicles induced any change in ear blood flow, systemic blood pressure, or heart rate in control experiments (data not shown).

In desensitization and cross-desensitization experiments, the putative desensitizing agent was injected i.p. 105 minutes before the onset of anesthesia, i.e., 120 minutes before the injection of the tested compound. In control experiments, we verified that the flushing effects of nicotinic acid and acipimox are completely reversed within 120 minutes and LDF returns to the baseline level (data not shown).

Evaluation of the flushing response and statistics. Original LDF recordings were averaged for 1-second intervals in order to obtain mean LDF without pulsation. In all experiments, baseline LDF was determined prior to injection of the tested compound. Nicotinic acid and acipimox induced biphasic flush, and therefore the maximal LDF values of the first and second flushing were determined and expressed as percentages of the baseline flow. All data are presented as mean \pm SEM. If 1 compound was tested several times in 1 animal, the results obtained were averaged. Between 2 experiments in the same animal, at least 1 week was allowed for recovery. Statistical analyses of differences between 2 groups was performed by unpaired, 2-tailed Student's $t$ test. Comparisons among 3 or more experimental groups were made by ANOVA followed by the Bonferroni post hoc test. A $P$ value of less than 0.05 was considered significant.

Bone marrow transplantation. Bone marrow transplantation was performed as described previously (57). Bone marrow was obtained aseptically from femurs and tibias of wild-type or PUMA-G ${ }^{-/-}$mice after euthanizing animals by cervical dislocation. Unfractionated bone marrow cells $\left(5 \times 10^{6}\right)$ were resuspended in sterile PBS and transplanted by tail-vein infusion into lethally irradiated (10 Gy) PUMA-G ${ }^{-/}$recipients 1 day after irradiation. Eight to 12 weeks later, successful engraftment was confirmed by PCR amplification of blood DNA using allele-specific probes.
Isolation of cells. Mouse ears were dissected and split into ventral and dorsal sheets. After 1-hour digestion in PBS containing trypsin $(0.5 \% \mathrm{w} / \mathrm{v})$ and 5 mM EDTA, the dermis was removed, and the pooled epidermal tissue was agitated to release cells. The cells were magnetically sorted using MHC class II (haplotype 1a) antibody coupled to magnetic beads (Miltenyi Biotec). Dendritic cells were stained with FITC anti-mouse CD86 and PE anti-MHC class II (IA/IE) (BD Biosciences - Pharmingen) and sorted using a FACS Vantage (BD) flow cytometer. Reanalysis of the sorted cells showed $74 \%$ of them to be $\mathrm{CD}^{2} 6^{+} / \mathrm{MHC}$ class $\mathrm{II}^{+}$. Monocytes were isolated from whole blood by gradient centrifugation using Lympholyte Mammal CL5115 (Cedarlane Laboratories Ltd.). The peritoneal cavities of mice were lavaged with $5 \mathrm{ml}$ RPMI medium in order to obtain peritoneal macrophages.

Measurement of $\left[\mathrm{Ca}^{2+}\right]_{i}$. Macrophages were allowed to adhere to $12-\mathrm{mm}-$ diameter glass covers and loaded with Fura-2/AM ( $3 \mu \mathrm{M}$, Molecular Probes; Invitrogen Corp.) for 60 minutes at room temperature. The nonadherent cells were removed by washing with Hank's balanced salt solution containing $2.5 \mathrm{mM} \mathrm{Ca}^{2+}$ and $5 \mathrm{mM}$ glucose. Ratiometric calcium signals were recorded using a Zeiss Axiovert 135 microscope, a SensiCam CCD camera (PCO AG), and TILLvisION software version 4.00 (TILL Photonics).

Northern blots and RT-PCR. Northern blot analysis and RT-PCR were performed as described (23). RNA was isolated with the Trizol Reagent (Invitrogen Corp.). For RT-PCR, $50 \mathrm{ng}$ to $1 \mu \mathrm{g}$ of total RNA were reverse transcribed. cDNA of a PUMA-G 560-bp fragment was performed with specific primers (sGTGTAGCAGCTTCAGCATCTGT; asGAGATGTGGAAGCCAGATAAGG). cDNA synthesis was monitored by PCR of a 401-bp fragment of glyceraldehyde 3-phosphate dehydrogenase.

\section{Acknowledgments}

The authors are grateful to Takayuki Maruyama (Ono Pharmaceutical Co.) and Shuh Narumiya for providing prostanoid receptor mutant mice. The expert technical assistance of Béla Horváth, Karin Meyer, Anke Rogatzki, and Zsolt Rácz is gratefully acknowledged. We would also like to thank Karsten Mahnke, Sabine Ring, and Nikolaus Romani for their advice on the isolation of dendritic cells and Manuel Scheuermann for help with FACS sorting. Z. Benyó was supported by a Marie Curie Individual Fellowship. A. Gille was supported by a long-term European Molecular Biology Organisation fellowship. J. Kero was supported by a fellowship from the Serono Foundation. M.C. Suchánková received a European Community Action Scheme for the Mobility of University Students (ERASMUS) scholarship. This work was supported by grants from the Deutsche Forschungsgemeinschaft and the Hungarian Scientific Research Fund (OTKA) (T037386).

Received for publication October 14, 2004, and accepted in revised form September 13, 2005.

Address correspondence to: Stefan Offermanns, Institute of Pharmacology, University of Heidelberg, Im Neuenheimer Feld 366, 69120 Heidelberg, Germany. Phone: 49-6221-548246; Fax: 496221-548549; E-mail: stefan.offermanns@urz.uni-heidelberg.de.
1. Carlson, L.A., and Oro, L. 1962. The effect of nicotinic acid on the plasma free fatty acid; demonstration of a metabolic type of sympathicolysis. Acta Med. Scand. 172:641-645.

2. Altschul, R., Hoffer, A., and Stephen, J.D. 1955. Influence of nicotinic acid on serum cholesterol in man. Arch. Biochem. 54:558-559.

3. Knopp, R.H. 1999. Drug treatment of lipid disorders. N. Engl. J. Med. 341:498-511.

4. Olsson, A.G. 1994. Nicotinic acid and derivatives.
In Handbook of experimental pharmacology. G. Schettler and A.J.R. Habenicht, editors. Springer-Verlag. Heidelberg, Germany. 349-400.

5. Shepherd, J., Packard, C.J., Patsch, J.R., Gotto, A.M., Jr., and Taunton, O.D. 1979. Effects of nicotinic acid therapy on plasma high density lipoprotein subfraction distribution and composition and on apolipoprotein A metabolism. J. Clin. Invest. 63:858-867.

6. Blum, C.B., et al. 1977. High density lipoprotein metabolism in man. J. Clin. Invest. 60:795-807.

7. Crouse, J.R., 3rd. 1996. New developments in the use of niacin for treatment of hyperlipidemia: new considerations in the use of an old drug. Coron. Artery Dis. 7:321-326.

8. Brown, W.V. 2001. Novel approaches to lipid lowering: what is on the horizon? Am. J. Cardiol. 87:23B-27B.

9. Szapary, P.O., and Rader, D.J. 2001. Pharmacological management of high triglycerides and low high- 
density lipoprotein cholesterol. Curr. Opin. Pharmacol. 1:113-120.

10. Gylling, H., and Miettinen, T.A. 2002. Combination therapy with statins. Curr. Opin. Investig. Drugs. 3:1318-1323.

11. Moon, Y.S., and Kashyap, M.L. 2002. Niacin extended-release/lovastatin: combination therapy for lipid disorders. Expert. Opin. Pharmacother. 3:1763-1771.

12. Spies, T.D., Cooper, C., and Blankenhorn, M.A. 1938. The use of nicotinic acid in the treatment of pellagra. JAMA. 110:622-627.

13. Goldsmith, G.A., and Cordill, S. 1943. The vasodilating effects of nicotinic acid (relation to metabolic rate and body temperature). Am. J. Med. Sci. 205:204-208

14. Hotz, W. 1983. Nicotinic acid and its derivatives: a short survey. Adv. Lipid Res. 20:195-217.

15. Andersson, R.G., Aberg, G., Brattsand, R., Ericsson, E., and Lundholm, L. 1977. Studies on the mechanism of flush induced by nicotinic acid. Acta Phar macol. Toxicol. (Copenh.). 41:1-10.

16. Eklund, B., Kaijser, L., Nowak, J., and Wennmalm, A. 1979. Prostaglandins contribute to the vasodilation induced by nicotinic acid. Prostaglandins. 17:821-830

17. Kaijser, L., Eklund, B., Olsson, A.G., and Carlson, L.A. 1979. Dissociation of the effects of nicotinic acid on vasodilatation and lipolysis by a prostaglandin synthesis inhibitor, indomethacin, in man. Med. Biol. 57:114-117.

18. Olsson, A.G., Carlson, L.A., Anggard, E., and Ciabattoni, G. 1983. Prostacyclin production augmented in the short term by nicotinic acid. Lancet. 2:565-566.

19. Nozaki, S., et al. 1987. Increased compliance of niceritrol treatment by addition of aspirin: relationship between changes in prostaglandins and skin flushing. Int. J. Clin. Pharmacol. Ther. Toxicol. 25:643-647.

20. Morrow, J.D., Parsons, W.G., 3rd, and Roberts, L.J., 2nd. 1989. Release of markedly increased quantities of prostaglandin D2 in vivo in humans following the administration of nicotinic acid. Prostaglandins. 38:263-274

21. Stern, R.H., Spence, J.D., Freeman, D.J., and Parbtani, A. 1991. Tolerance to nicotinic acid flushing. Clin. Pharmacol. Ther. 50:66-70.

22. Wise, A., et al. 2003. Molecular identification of high and low affinity receptors for nicotinic acid. J. Biol. Chem. 278:9869-9874.

23. Tunaru, S., et al. 2003. PUMA-G and HM74 are receptors for nicotinic acid and mediate its antilipolytic effect. Nat. Med. 9:352-355.

24. Soga, T., et al. 2003. Molecular identification of nicotinic acid receptor. Biochem. Biophys. Res. Commun. 303:364-369.

25. Edlund, A., Musatti, L., and Wennmalm, A. 1990. Acipimox stimulates skin blood flow by a cyclooxygenase-dependent mechanism. Eur. J. Clin. Pharmacol. 39:37-41.

26. Tornvall, P., and Walldius, G. 1991. A comparison between nicotinic acid and acipimox in hypertriglyceridaemia-effects on serum lipids, lipoproteins, glucose tolerance and tolerability. J. Intern. Med. 230:415-421.

27. Pontiroli, A.E., et al. 1992. Acipimox-induced facial skin flush: frequency, thermographic evaluation and relationship to plasma acipimox level. Eur. J. Clin. Pharmacol. 43:145-148.

28. Langenbach, R., et al. 1995. Prostaglandin synthase 1 gene disruption in mice reduces arachidonic acidinduced inflammation and indomethacin-induced gastric ulceration. Cell. 83:483-492.

29. Huang, P.L., et al. 1995. Hypertension in mice lacking the gene for endothelial nitric oxide synthase. Nature. 377:239-242.

30. Negishi, M., Sugimoto, Y., and Ichikawa, A. 1995. Molecular mechanisms of diverse actions of prostanoid receptors. Biochim. Biophys. Acta. 1259:109-119

31. Narumiya, S., Sugimoto, Y., and Ushikubi, F. 1999. Prostanoid receptors: structures, properties, and functions. Physiol. Rev. 79:1193-1226.

32. Hata, A.N., and Breyer, R.M. 2004. Pharmacology and signaling of prostaglandin receptors: Multiple roles in inflammation and immune modulation. Pharmacol. Ther. 103:147-166.

33. Nguyen, M., et al. 1997. The prostaglandin receptor EP4 triggers remodelling of the cardiovascular system at birth. Nature. 390:78-81.

34. Murata, T., et al. 1997. Altered pain perception and inflammatory response in mice lacking prostacyclin receptor. Nature. 388:678-682

35. Hizaki, H., et al. 1999. Abortive expansion of the cumulus and impaired fertility in mice lacking the prostaglandin E receptor subtype EP(2). Proc. Natl. Acad. Sci. U. S. A. 96:10501-10506.

36. Matsuoka, T., et al. 2000. Prostaglandin D2 as a mediator of allergic asthma. Science. 287:2013-2017.

37. Schaub, A., Futterer, A., and Pfeffer, K. 2001. PUMA-G, an IFN-gamma-inducible gene in macrophages is a novel member of the seven transmembrane spanning receptor superfamily. Eur. J. Immunol. 31:3714-3725.

38. Meyers, C.D., and Kashyap, M.L. 2004. Pharmacologic elevation of high-density lipoproteins: recent insights on mechanism of action and atherosclerosis protection. Curr. Opin. Cardiol. 19:366-373.

39. Karpe, F., and Frayn, K.N. 2004. The nicotinic acid receptor--a new mechanism for an old drug. Lancet. 363:1892-1894.

40. Carlson, L.A. 1978. Nicotinic acid and inhibition of fat mobilizing lipolysis. Present status of effects on lipid metabolism. Adv. Exp. Med. Biol. 109:225-238.

41. Rohte, O., Thormahlen, D., and Ochlich, P. 1977. Elucidation of the mechanism of nicotinic acid flush in the animal experiment [In German]. Arzneimittelforschung. 27:2347-2352.

42. Hofmann, F. 2004. Smooth muscle tone regulation. In Encyclopedic reference of molecular pharmacology. S. Offermanns and W. Rosenthal, editors. Springer-Verlag. Berlin, Germany. 870-874.

43. Breyer, R.M., Bagdassarian, C.K., Myers, S.A., and
Breyer, M.D. 2001. Prostanoid receptors: subtypes and signaling. Annu. Rev. Pharmacol. Toxicol. 41:661-690.

44. Hata, A.N., Zent, R., Breyer, M.D., and Breyer, R.M. 2003. Expression and molecular pharmacology of the mouse CRTH2 receptor. J. Pharmacol. Exp. Ther. 306:463-470.

45. Exton, J.H. 2004. Phospholipases. In Encyclopedic reference of molecular pharmacology. S. Offermanns and W. Rosenthal, editors. Springer-Verlag. Berlin, Germany. 733-739.

46. Six, D.A., and Dennis, E.A. 2000. The expanding superfamily of phospholipase A(2) enzymes: classification and characterization. Biochim. Biophys. Acta. 1488:1-19.

47. Richelsen, B. 1992. Release and effects of prostaglandins in adipose tissue. Prostaglandins Lenkot. Essent. Fatty Acids. 47:171-182.

48. Borglum, J.D., Richelsen, B., Darimont, C., Pedersen, S.B., and Negrel, R. 1997. Expression of the two isoforms of prostaglandin endoperoxide synthase (PGHS-1 and PGHS-2) during adipose cell differentiation. Mol. Cell. Endocrinol. 131:67-77.

49. Morrow, J.D., Awad, J.A., Oates, J.A., and Roberts, L.J., 2nd. 1992. Identification of skin as a major site of prostaglandin D2 release following oral administration of niacin in humans. J. Invest. Dermatol. 98:812-815.

50. Exton, J.H. 1996. Regulation of phosphoinositide phospholipases by hormones, neurotransmitters, and other agonists linked to G proteins. Annu. Rev. Pharmacol. Toxicol. 36:481-509.

51. Rhee, S.G. 2001. Regulation of phosphoinositide-specific phospholipase C. Annu. Rev. Biochem. 70:281-312.

52. Kitamura, Y., Go, S., and Hatanaka, K. 1978. Decrease of mast cells in $\mathrm{W} / \mathrm{Wv}$ mice and their increase by bone marrow transplantation. Blood. 52:447-452.

53. Nakano, T., Kanakura, Y., Nakahata, T., Matsuda, H., and Kitamura, Y. 1987. Genetically mast celldeficient $\mathrm{W} / \mathrm{Wv}$ mice as a tool for studies of differentiation and function of mast cells. Fed. Proc. 46:1920-1923.

54. Ruzicka, T., and Aubock, J. 1987. Arachidonic acid metabolism in guinea pig Langerhans cells: studies on cyclooxygenase and lipoxygenase pathways. J. Immunol. 138:539-543.

55. Urade, Y., Ujihara, M., Horiguchi, Y., Ikai, K., and Hayaishi, O. 1989. The major source of endogenous prostaglandin D2 production is likely antigen-presenting cells. Localization of glutathione-requiring prostaglandin D synthetase in histiocytes, dendritic, and Kupffer cells in various rat tissues. J. Immunol. 143:2982-2989.

56. Harizi, H., Juzan, M., Grosset, C., Rashedi, M., and Gualde, N. 2001. Dendritic cells issued in vitro from bone marrow produce PGE(2) that contributes to the immunomodulation induced by antigen-presenting cells. Cell Immunol. 209:19-28.

57. Moers, A., et al. 2003. G13 is an essential mediator of platelet activation in hemostasis and thrombosis. Nat. Med. 9:1418-1422. 